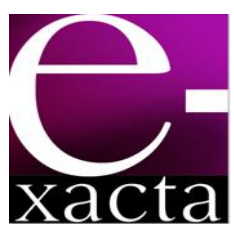

ISSN: 1984-3151

\title{
HidRólise ENZIMÁtICA do Óleo de CRAMBE (CRAMBE ABYSSINICA H.) ASSISTIDA POR ULTRASSOM
}

\section{ENZYMATIC HYDROLYSIS OF CRAMBE OIL (CRAMBE ABYSSINICA H.) ASSISTED BY ULTRASOUND}

\author{
Bruna Tais Ferreira de Mello; Giovana de Menezes Rodrigues ${ }^{2}$; Camila da Silva $^{3}$ \\ 1 Mestranda em Bioenergia. Universidade Estadual de Maringá, \\ 2015. Graduada em Química Industrial, Universidade \\ Paranaense. Umuarama, PR. brunamellosip@hotmail.com. \\ 2 Graduanda em Engenharia de Alimentos. Universidade \\ Estadual de Maringá, 2016. Umuarama, PR. \\ giovanamr@hotmail.com.br. \\ 3 Doutora em Engenharia Química. Universidade Estadual de \\ Maringá, 2009. Professora do Departamento de Tecnologia. \\ Universidade Estadual de Maringá, Umuarama, PR. \\ camiladasilva.eq@gmail.com.
}

Recebido em: 18/03/2015 - Aprovado em: 26/05/2015 - Disponibilizado em: 30/05/2015

RESUMO: O presente trabalho teve como objetivo a obtenção de hidrolisado, rico em ácidos graxos livres (AGL), a partir do óleo de crambe. Os experimentos foram conduzidos em banho de ultrassom, utilizando a enzima Lipozyme® TL IM como catalisador em meio livre de solvente orgânico. O efeito do ultrassom na reação, efeito do teor de água, temperatura, percentual de catalisador e tempo de reação é avaliado. A adição de elevados teores de água no meio reacional, $40 \%$ (em relação à massa de óleo), e temperatura de $45^{\circ} \mathrm{C}$ favoreceram a produção de AGL. O aumento da concentração de enzima no meio reacional favoreceu a obtenção de AGL na faixa de 7,5 a $12,5 \%$, sendo que os melhores rendimentos ( $78 \%$ em AGL) foram obtidos em 6 horas. A aplicação do ultrassom favoreceu a produção de AGL $(p<0,05)$.

PALAVRAS-CHAVE: Hidrólise enzimática. Ultrassom. Óleo de crambe.

ABSTRACT: This study aimed to obtain hydrolyzate, rich in free fatty acids (FFA), from crambe oil. The experiments were conducted in an ultrasound bath, using the Lipozyme® TL IM enzyme as a catalyst in organic solvent-free medium. The effect of ultrasound on the reaction, effect of water content, temperature, percentage of catalyst and reaction time is evaluated. The addition of high water content in the reaction medium, $40 \%$ (relative to oil mass), and temperature of $45^{\circ} \mathrm{C}$ favor the production of FFA. Increasing the enzyme concentration in the reaction medium favored the production of FFA, in the range from 7.5 to $12.5 \%$, and the best yields ( $78 \%$ for FFA) were obtained within 6 hours. The application of ultrasound favors the production of FFA $(p<0.05)$.

KEYWORDS: Enzymatic hydrolysis. Ultrasound. Crambe oil.

\section{INTRODUÇÃO}

A hidrólise de triacilglicerídeos ocorre na interface entre as duas fases, uma vez que estes substratos são imiscíveis entre si. O contato entre as duas fases é usualmente promovido por agitação mecânica, especialmente a nível industrial, mas recentemente têm-se tentado solucionar este problema através da aplicação do ultrassom (YU et al., 2010; FEITEN et al., 2014). Nas reações assistidas por irradiação ultrassônica, as cavitações (formação, aumento e implosão de bolhas no meio da reação) geradas pelo ultrassom, aumentam a miscibilidade entre os 
reagentes, aumentando a transferência de massa entre as duas fases através do fornecimento de aquecimento e de mistura (VELJKOVIĆ et al., 2012). A cavitação provoca um aumento localizado de temperatura na fronteira das fases e fornece a energia mecânica para a mistura e a energia de ativação necessária para iniciar a reação. O colapso das bolhas de cavitação rompe a fronteira de fase e promove a emulsificação por jatos ultrassônicos. Estes efeitos proporcionam o aumento das taxas de reação e a obtenção de elevados rendimentos (THANK et al., 2010), com pouca quantidade de catalisador e menor energia é consumida quando comparado ao processo com agitação mecânica (CHAND et al., 2010). Entre os catalisadores utilizados para hidrólise de óleos vegetais, as enzimas imobilizadas apresentam como principais atrativos a facilidade de separação do catalisador do meio reacional, a não geração de efluentes, a pureza do glicerol gerado como subproduto, além da possibilidade de reutilização (RANGANATHAN; NARASIMHAN; MUTHUKUMAR, 2008; JERBAEK; CHRISTENSEN; NORDDAHL, 2009), podendo ser conduzida em temperaturas amenas, que previne a degradação dos produtos e reduz os custos energéticos (ANTCZAK et al., 2009). Entretanto, o uso destes catalisadores imobilizados apresenta como inconveniente a limitação na transferência de massa, uma vez que, os suportes podem dificultar o acesso dos substratos ao seu sítio catalítico (JERBAEK; CHRISTENSEN; NORDDAHL, 2009). Lerin et al. (2014) citam que isso pode ser minimizado com a utilização do ultrassom, visto que em reações assistidas por ultrassom tem-se 0 aumento do movimento das moléculas do líquido e o acesso do substrato ao sítio ativo da enzima. Entre os produtos da hidrólise, os ácidos graxos livres (AGL) apresentam diversas aplicações, como em indústrias de sabões, agentes tensoativos, lubrificantes, plásticos, tintas, revestimentos, produtos farmacêuticos, alimentos, produtos de higiene pessoais, entre outros (SATYARTHI; SRINIVAS; RATNASAMY, 2011; AVELAR et al., 2013), além dos mesmos serem utilizados como substratos para a produção de biodiesel a partir da esterificação (TALUKDER; WU; CHUA, 2010; MENG et al., 2011; TAKISAWA et al., 2013; AGUIEIRAS et al., 2014).

A obtenção de AGL para a produção de biodiesel deve ser focada em matérias primas de baixo custo e sem fins alimentícios. Dentre as quais, o crambe (Crambe abyssinica H.) surgiu como uma boa opção, por ser uma planta com alto teor de óleo com uma cultura de ciclo curto, em média 90 dias, e com produtividade entre 1.000 e 1.500 quilogramas por hectare (SILVA et al., 2013). As sementes de crambe possuem em torno de 34 a $45 \%$ de óleo (SILVA; REIS; MACIEL, 2012; SANTOS et al., 2013; VIANA et al., 2013; BRANDÃO et al., 2014; PRATES et al., 2014), com predominância do ácido erúcico (56-66 \%), tornando o mesmo impróprio para o consumo humano (WAZILEWSKI et al., 2013; MACIEL et al., 2014), visto que este ácido graxo monoinsaturado de cadeia longa é tóxico para a saúde por causar danos cardíacos, como o aumento do nível de colesterol e lipidose nos tecidos do coração (GOSWAMI; BASU; DE, 2012). Dessa forma, - cultivo de crambe pode ser destinado exclusivamente para fins industriais e produção de biocombustíveis.

Com base no contexto descrito, o foco deste trabalho foi a obtenção de hidrolisado do óleo de crambe, rico em AGL, a ser utilizado em reações de esterificação para produção de biodiesel. Para este fim, as reações foram conduzidas em banho de ultrassom com contato indireto e catálise enzimática. 


\section{MATERIAIS E MÉtodos}

\subsection{MATERIAIS}

A enzima de Thermomyces lanuginosus (Lipozyme® TL IM) cedida pela LNF Latino Americana foi utilizada como catalisador. Como substratos foram utilizados óleo de crambe (Fundação MS) e água destilada. A composição do óleo em termos de ácidos graxos é apresentada na TAB. 1, sendo que o mesmo apresentou $1,88 \pm 0,1 \mathrm{mg} 100 \mathrm{mg}^{-1}$ de ácidos graxos livres (AGL) e 0,016 \% de água. Para determinação do teor de AGL nas amostras foram utilizados éter etílico, etanol, hidróxido de sódio e o indicador fenolftaleína.

Tabela 1

Composição química do óleo de crambe.

\begin{tabular}{cc}
\hline Ácido Graxo & Percentual (\%) \\
\hline Palmítico & $1,95 \pm 0,14$ \\
Palmitoleico & $0,16 \pm 0,01$ \\
Esteárico & $0,98 \pm 0,04$ \\
Oleico & $17,43 \pm 0,60$ \\
cis-vacênico & $0,46 \pm 0,04$ \\
Linoleico & $7,46 \pm 0,26$ \\
Linolênico & $4,23 \pm 0,59$ \\
Araquídico & $1,17 \pm 0,01$ \\
Eicosadienoico & $1,08 \pm 0,01$ \\
Erúcico & $58,39 \pm 0,01$ \\
\hline
\end{tabular}

\subsection{Procedimento}

As reações foram conduzidas em um Erlenmeyer de vidro de $50 \mathrm{~mL}$, conectado a banho ultrassônico com controle da temperatura (Ultronique, Q $5.9 / 40 \mathrm{~A}$ ) e agitador mecânico (IKA RW 20 D). A enzima foi colocada em estufa a $40 \stackrel{\circ}{ } \mathrm{C}$ por 1 hora para ativação.
Os substratos foram adicionados ao reator, sendo o mesmo acoplado ao banho ultrassom dando início ao aquecimento. Após atingida a temperatura de reação, a enzima era adicionada ao meio, e iniciada a agitação do sistema com o fornecimento de irradiação ultrassônica. Os experimentos foram realizados com agitação em 600 rpm e potência do banho ultrassônico de $132 \mathrm{~W}$, tais condições definidas baseadas no trabalho de Feiten et al. (2014). No final da reação, a enzima foi removida por filtração. As amostras foram transferidas para tubos de centrífuga e submetidas à centrifugação por 10 minutos a $3500 \mathrm{rpm}$. Posteriormente, a fase oleosa contendo os AGLs foi transferida para frascos de amostragem e levada à estufa com circulação de $\operatorname{ar}\left(80^{\circ} \mathrm{C}\right)$ até atingir peso constante. Por fim, as mesmas foram refrigeradas para posterior análise.

O percentual de ácidos graxos livres nas amostras foi determinado com base no método $\mathrm{Ca} 5 \mathrm{a}-40$ (WALKER, 1998), a partir da Eq. 1:

$$
A G L s(\%)=\frac{V \cdot C \cdot M M}{10 \cdot m}
$$

onde: $\mathrm{V}=$ volume da solução utilizada para a titulação $(\mathrm{mL}), \mathrm{MM}=$ massa molar média dos AGLs do óleo de crambe determinada utilizando os dados da TAB. 1 $\left(314,51 \mathrm{~g} \mathrm{~mol}^{-1}\right), C=$ concentração da solução de hidróxido de sódio $\left(\mathrm{mol} \mathrm{L}^{-1}\right)$ e $\mathrm{m}=$ massa da amostra (g).

Os dados obtidos foram submetidos à análise de variância, analisados pela ANOVA e teste de Tukey $(p>0,05)$ para avaliar as diferenças das médias dos tratamentos.

e-xacta, Belo Horizonte, v. 8, n.1, p.77-85. (2015). Editora UNIBH. Disponível em: www.unibh.br/revistas/exacta/ 


\section{Resultados e Discussão}

\subsection{EFEITO dO TEOR DE ÁGUA}

O efeito o teor de água (em relação à massa de óleo) na hidrólise de óleo de crambe foi avaliada mantendose a temperatura fixa em $65{ }^{\circ} \mathrm{C}$, percentual de catalisador a $10 \%$ (em relação aos substratos), e tempos de reação de 2 e 4 horas (FIG. 1). A partir da FIG. 1 pode-se verificar que o aumento da quantidade de água no meio reacional, na faixa de 20 a $40 \%$, favorece a produção de AGLs. No entanto, quando um excesso de água foi aplicado ao meio (50 \%), não houve nenhum efeito significativo sobre o rendimento $(p>0,05)$ nas condições avaliadas. O trabalho de Huang et al. (2010) reporta que a taxa inicial da reação de hidrólise conduzida em banho de ultrassom é influenciada pela fração volumétrica de óleo no meio reacional, sendo que a mesma atinge valores máximos em frações de 0,6 a $0,7 \quad(\mathrm{v} / \mathrm{v})$ o que corresponde a $\sim 40 \%$ e $50 \%$ de água. Alves et al. (2014) relatam que o aumento do teor de água afeta positivamente a taxa de hidrólise, visto que a água é um fator importante para manter a atividade $e$ estabilidade das enzimas. A alta concentração de óleo no meio ocasiona a saturação dos sítios ativos das enzimas e reduz a taxa de difusão dos substratos e produtos ao sítio ativo (CHUA et al., 2012).

Liu et al. (2008) ao investigarem o efeito do ultrassom na hidrólise enzimática de óleo de soja, relatam que maiores quantidades de água no meio reacional, na faixa de 10 a $30 \%$, resultam no aumento da produção de AGL. Na hidrólise enzimática do óleo de buriti, Ribeiro, Coelho e Barreto (2012) observaram o acréscimo nos rendimentos em AGL de 56,6 \% para $62,9 \%$ utilizando razões mássicas de óleo:água 14 e $26 \%$, respectivamente utilizando a enzima TL IM. Raspe, Cardozo-Filho e Silva (2013) reportaram o efeito significativo do percentual de água de 10 a $50 \%$ no meio reacional de hidrólise do óleo de macaúba, utilizando a enzima Lipozyme® TL IM. Oliveira et al. (2011) reportaram que o aumento da concentração de óleo no meio reacional, na faixa de 55 a $91 \%$ (v/v) não favoreceu a produção de AGL a partir da hidrólise de óleo de soja catalisada pela enzima de Thermomyces lanuginosus. Bressani et al. (2015) reportam que o aumento do teor de água no meio reacional de 20 a $40 \%$ favoreceu a obtenção de $A G L$ do óleo de macaúba utilizando extrato enzimático bruto obtido de sementes de mamona.

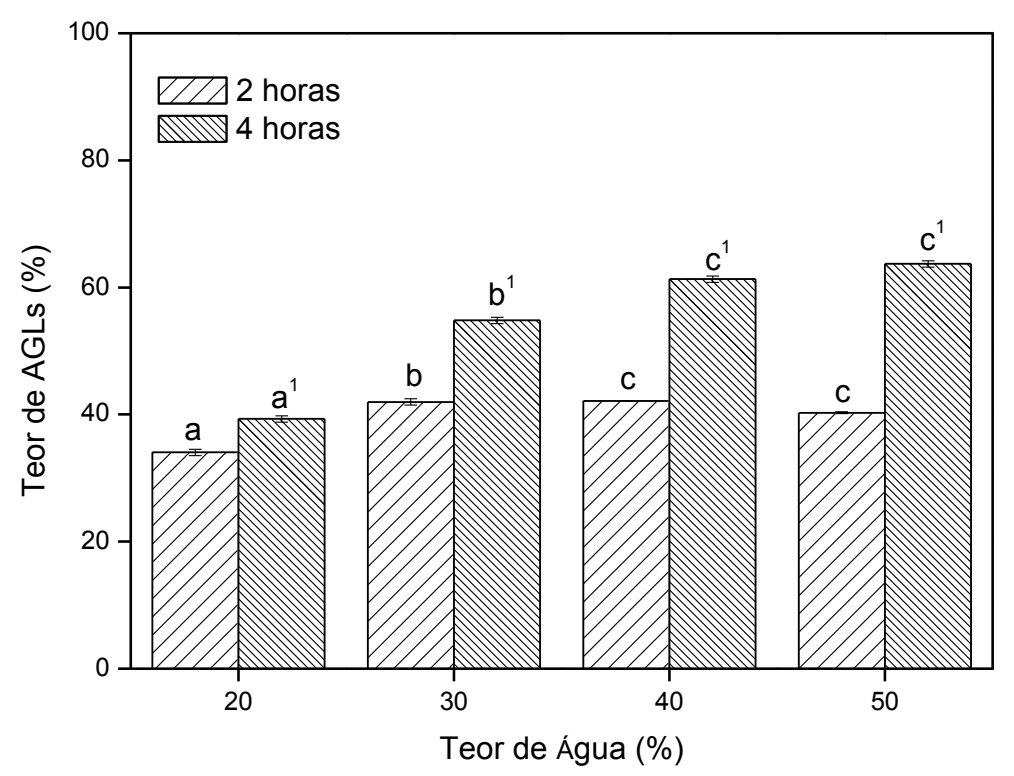

Figura 1 - Efeito do teor de água na hidrólise enzimática do óleo de crambe. Médias seguidas de mesmas letras (para um mesmo tempo de reação), em cada coluna, não se diferem estatisticamente $(p>0,05)$. 


\subsection{EFEITO DA TEMPERATURA}

Na FIG. 2 pode-se observar o efeito da temperatura, avaliada no intervalo de 35 a $65{ }^{\circ} \mathrm{C}$, utilizando $40 \%$ de água (em relação à massa de óleo), percentual de catalisador de $10 \%$ (em relação à massa dos substratos) e tempos de reação de 2 e 4 horas. A partir da FIG. 2 pode-se observar que o aumento da temperatura proporcionou maior produção de AGL no intervalo de 35 a $45{ }^{\circ} \mathrm{C}$, obtendo em 4 horas de reação 65,4 e 69,9 \%, respectivamente. O aumento da temperatura elevou a frequência de colisão entre as enzimas e os substratos, resultando no avanço da taxa de reação (SOO et al., 2003). Duan et al. (2010) ressaltam que a viscosidade da mistura é reduzida com o aumento da temperatura e com isso ocorre 0 acréscimo do processo de difusão dos substratos, aumentando assim a transferência de massa que favorece a interação entre as enzimas e substratos. A alta temperatura favorece a obtenção de rendimentos mais elevados para reações endotérmicas, devido à mudança do equilíbrio termodinâmico (VIKBJERG et al., 2005). No entanto, um aumento adicional de temperatura pode conduzir a desnaturação das enzimas, reduzindo o seu poder catalítico. Nos experimentos realizados, constatou-se que com o aumento da temperatura para 55 e $65 \stackrel{\circ}{\circ}$ ocorreu o decréscimo na produção de AGL.

O trabalho de Chua et al. (2012) reporta o efeito favorável do aumento da temperatura de 30 a $45{ }^{\circ} \mathrm{C}$ na hidrólise do óleo virgem de coco utilizando a lípase imobilizada de Mucor miehei. Ribeiro, Coelho e Barr (2012) reportam que a temperatura de $45 \stackrel{\circ}{\circ}$ forneceu os melhores resultados na obtenção de AGL do óleo refinado de buriti (Mauritia vinífera) utilizando a enzima de Lipozyme® TL IM. Os resultados obtidos por Prado e Saldaña (2013) reportam que o aumento da temperatura de 40 para $60{ }^{\circ} \mathrm{C}$ na condução da hidrólise do óleo de Phukenetia volubilis não ocasionou efeito significativo nos percentuais de AGL.

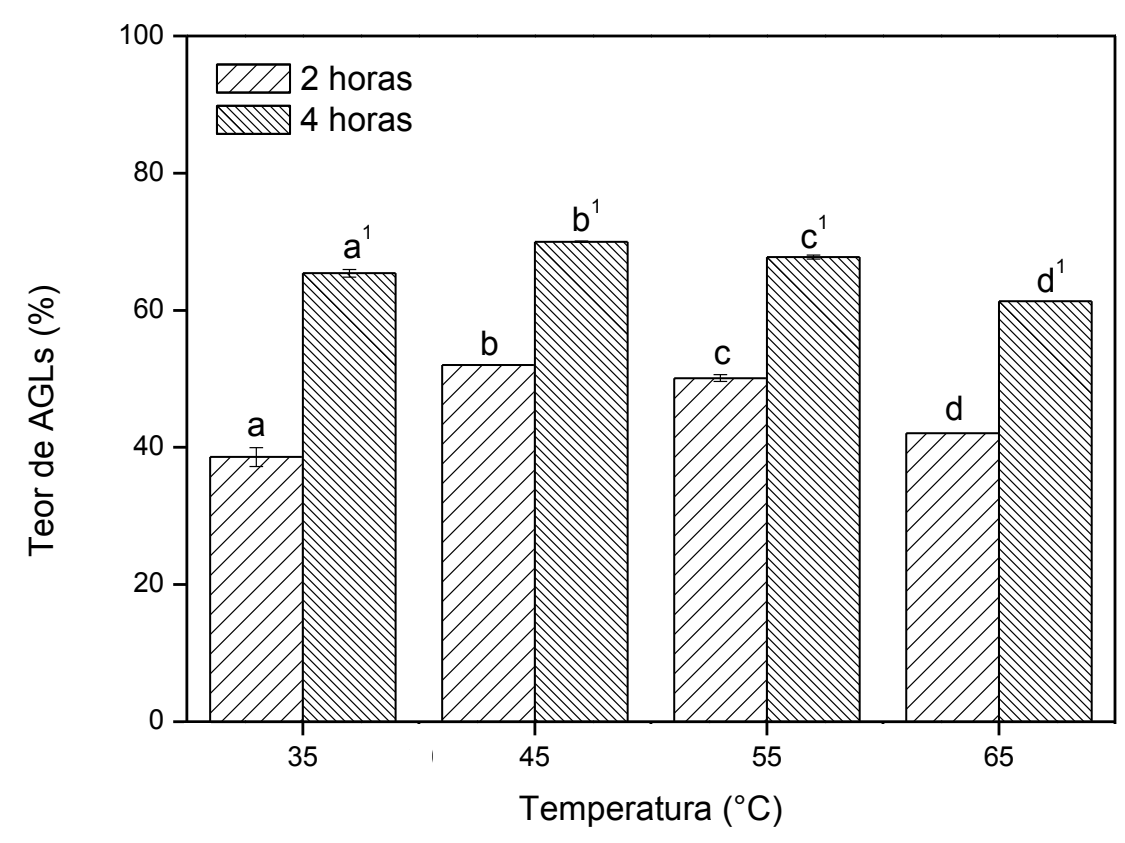

Figura 2 - Efeito da temperatura na hidrólise enzimática do óleo de crambe. Médias seguidas de mesmas letras (para um mesmo tempo de reação), em cada coluna, não se diferem estatisticamente $(p>0,05)$. 


\subsection{Efeito do Percentual de Catalisador e}

\section{TEMPO DE REAÇÃo}

O efeito do percentual de catalisador na reação de hidrólise foi avaliado considerando os percentuais de $7,5,10,12,5$ e $15 \%$ (em relação à massa de substratos) em tempos de reação de 1, 2, 4 e 8 horas, fixando-se a temperatura em $45{ }^{\circ} \mathrm{C}$ e utilizando-se $40 \%$ de água (em relação à massa de óleo), conforme apresentado pela FIG. 3. A análise dos dados demonstrou que tempos de reação $\geq 4$ horas apresentaram rendimentos $>60 \%$ para as diferentes concentrações de catalisador utilizadas. Para tempos $\geq 4$ horas, o aumento do percentual de catalisador de 12,5 para $15 \%$ não ocasionou efeito significativo no teor de AGL, desta forma, observam-se maiores rendimentos com 6 horas de reação ( 78 \%) e 12,5\% de catalisador.
Os resultados obtidos neste estudo podem ser comparados com trabalhos na literatura utilizando a enzima Lipozyme® TL IM, como o trabalho de Prado e Saldaña (2013) que relata a obtenção de $\sim 66 \%$ de AGL na hidrólise do óleo de Phukenetia volubilis utilizando $40 \%$ de enzima, razão molar óleo:água de $1: 5$, temperatura de $40 \stackrel{\circ}{\circ}$ e 6 horas de reação. A partir da comparação deste trabalho com os resultados obtidos neste estudo, verificou-se que com o aumento da concentração de água no meio reacional e uso do ultrassom, foi possível a obtenção de rendimentos superiores e com menor percentual de enzima. Ainda possibilitou a obtenção de teores de AGL superiores ao reportados no trabalho de Alves et al. (2014) que obtiveram $~ 50 \%$ de AGL na temperatura de $53^{\circ} \mathrm{C}$, razão molar óleo:água de $1: 12$, 8 horas de reação e $16 \%$ de enzima.

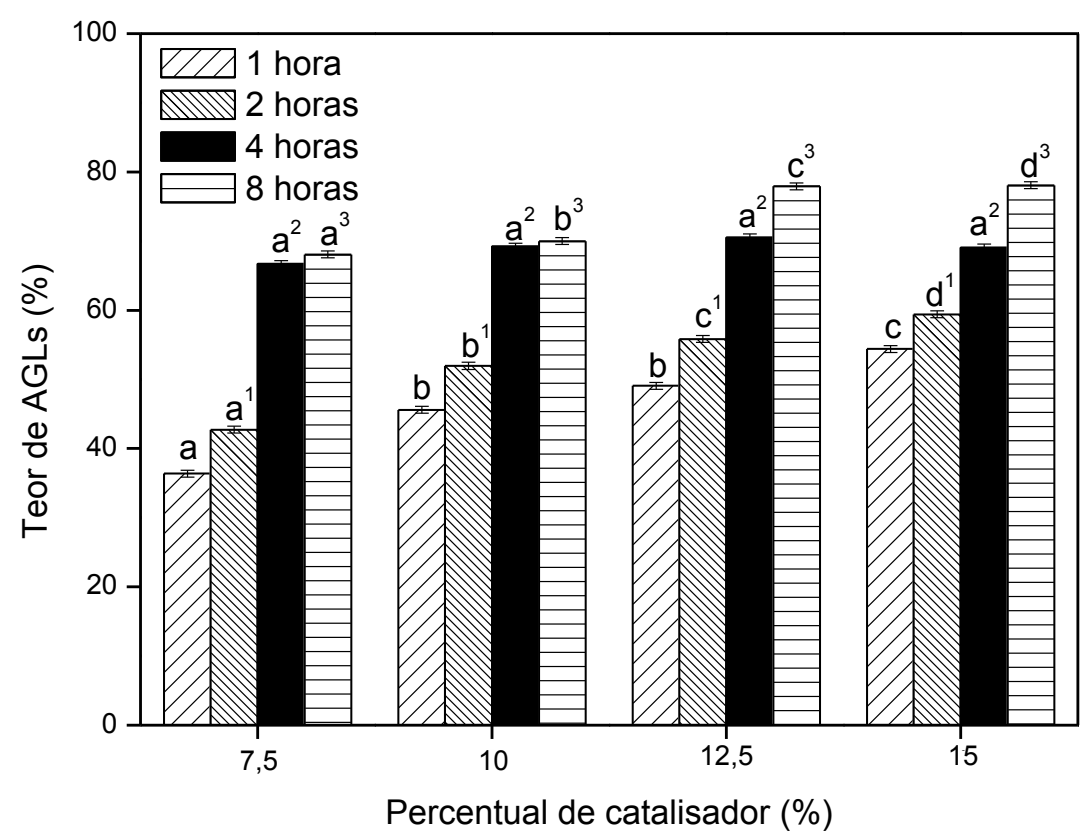

Figura 3 - Efeito do percentual de catalisador e do tempo de reação na hidrólise enzimática do óleo de crambe, sob $45^{\circ} \mathrm{C}, 600 \mathrm{rpm}$ e $40 \%$ de água (em relação à massa de óleo). 


\subsection{EFEITO DO ULTRASSOM}

O efeito do ultrassom sobre a hidrólise de óleo de crambe foi avaliado mantendo-se a temperatura fixa em $45{ }^{\circ} \mathrm{C}$, percentual de catalisador de $10 \%$ (em relação aos substratos) e $40 \%$ de água (em relação à massa de óleo) (FIG. 4). Os resultados apresentados na FIG. 4 demonstraram que as reações sob o efeito do ultrassom ocasionaram maiores teores de AGLs nos tempos de reação considerados $(p<0,05)$. Liu et al. (2008) destacam que 0 uso do ultrassom proporciona o aumento no rendimento em AGLs devido à crescente transferência de massa que o ultrassom proporciona no meio da reação. O estudo de Huang et al. (2010) compara a dispersão do óleo na água utilizando banho de água e banho de ultrassom, e reporta que maior área interfacial e menor tamanho de gota foram obtidos com a aplicação de irradiação ultrassônica e desta forma, obteve-se o aumento da taxa inicial de hidrólise.

O efeito favorável na formação de AGL a partir da reação de hidrólise é reportada nos trabalhos de Awadallak et al. (2013) na hidrólise enzimática do óleo de palma e Feiten et al. (2014) e Liu et al. (2008) na hidrólise do óleo de soja.

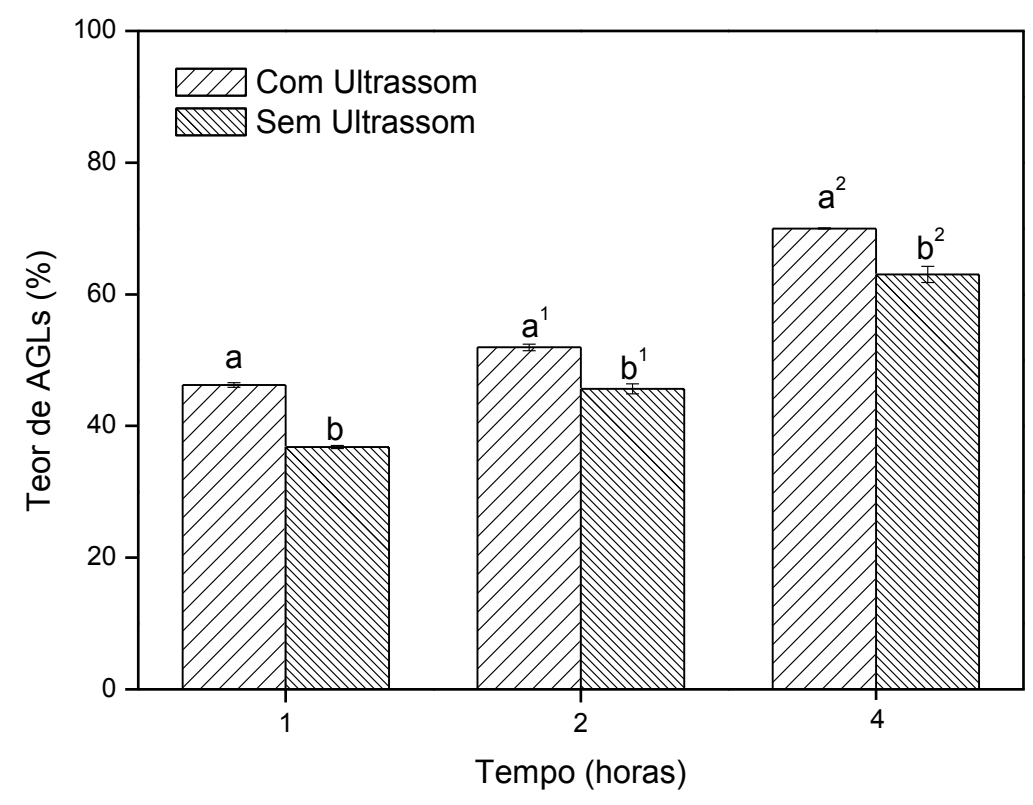

Figura 4 - Efeito do ultrassom na hidrólise enzimática do óleo de crambe. Médias seguidas de mesmas letras, para um mesmo tempo de reação, não se diferem estatisticamente $(p>0,05)$.

\section{ConCLUSÃo}

A obtenção de hidrolisado do óleo de Crambe assistida por irradiação ultrassônica foi reportada. Maiores teores de AGLs foram obtidos com adição de $40 \%$ de água no meio reacional e temperatura de $45 \stackrel{\circ}{ } \mathrm{C}$. O aumento da concentração de catalisador e tempo de reação proporcionou maiores rendimentos em AGLs, sendo possível obter $\sim 78 \%$ de conversão em 8 horas de reação.

\section{AgRADECIMENTOS}

Os autores agradecem à LNF Latino Americana pela doação das enzimas, à Fundação Araucária pelo suporte financeiro, à CAPES pela concessão da bolsa de estudos e a Universidade Estadual de Maringá Campus Regional de Umuarama pela infraestrutura. 


\section{REFERÊNCIAS}

AGUIEIRAS, E. C. G. et al. Biodiesel production from Acrocomia aculeata acid oil by (enzyme/enzyme) hydroesterification process: Use of vegetable lipase and fermented solid as low-cost biocatalysts. Fuel, v. 135, 315-321, 2014.

ALVES, J. S. et al. Combi-lipase for heterogeneous substrates: a new approach for hydrolysis of soybean oil using mixtures of biocatalysts. The Royal Society of Chemistry, v. 4, 6863-6868, 2014.

ANTCZAK, M. S. et al. Enzymatic biodiesel synthesiskey factors affecting efficiency of the process. Renewable Energy, v. 34, 1185-1194, 2009.

AVELAR, M. H. M. et al. Hydrolysis of vegetable oils catalyzed by lipase extract powder from dormant castor bean seeds. Industrial Crops and Products, v. $44,452-458,2013$.

AWADALLAK, J. A. et al. Enzymatic catalysed palm oil hydrolysis under ultrasound irradiation: Diacylglycerol synthesis. Ultrasonic Sonochemistry, v. 20, 10021007, 2013.

BRANDÃO, A. G. et al. Initial development of crambe due to sowing in different depths. African Journal of Agricultural Research, v. 9, 927-930, 2014.

BRESSANI, A. P. P. et al. Production of alkyl esters from macaw palm oil by a sequential hydrolysis/esterification process using heterogeneous biocatalysts: optimization by response surface methodology. Bioprocess and Biosystems Engineering, v. 38, 287-297, 2015.

CHAND, P. et al. Enhancing biodiesel production from soybean oil using ultrasonics. Energy Fuels, v. 24, 2010-2015, 2010.

CHUA, L. S. et al. Hydrolysis of Virgin Coconut Oil Using Immobilized Lipase in a Batch Reactor. Enzyme Research, v. 2012, 1-5, 2012.

DUAN, Z. Q. et al. Novozym 435-catalyzed 1,3diacylglycerol preparation via esterification in $t$-butanol system. Process Biochemistry, v. 45, 1923-1927, 2010.

FEITEN, M. C. et al. Batch and fed-batch enzymatic hydrolysis of soybean oil under ultrasound irradiation. Biocatalysis Agricultural Biotechnology, v. 01, 0103, 2014.
GOSWAMI, D.; BASU, J. K.; DE, S. Optimal hydrolysis of mustard oil to erucic acid: A biocatalytic approach. Chemical Engineering Journal, v. 182, 542-548, 2012.

HUANG, J. et al. Kinetic study on the effect of ultrasound on lipase-catalyzed hydrolysis of soy oil: Study of the interfacial area and the initial rates. Ultrasonics Sonochemistry, v. 17, 521-525, 2010.

JERBAEK, L.; CHRISTENSEN, K. V.; NORDDAHL, B. $A$ review of the current state of biodiesel production using enzymatic transesterification. Biotechnology and Bioengineering, v. 102, n. 5, 1298-1302, 2009.

LERIN, L. A. et al. A review on lipase-catalyzed reactions in ultrasound-assisted systems. Bioprocess and Biosystems Engineering, v. 37, n. 12, 23812394, 2014.

LIU, Y. et al. The effect of ultrasound on lipasecatalyzed hydrolysis of soy oil in solvent-free system. Ultrasonic Sonochemistry, v. 15, 402-407, 2008.

MACIEL, A. M. et al. Phisicochemical properties of interesterified blends of fully hydrogenated Crambe abyssica oil and soybean oil. Journal Of American Oil Chemical Society, v. 91, 111-123, 2014.

MENG, Y. et al. Two-step synthesis of fatty acid ethyl ester from soybean oil catalyzed by Yarrowia lipolytica lipase. Biotechnology for Biofuels, v. 4, 1-9, 2011.

OLIVEIRA, E. A. C.; et al. Study of Soybean Oil Hydrolysis Catalyzed by Thermomyces lanuginosus Lipase and Its Application to Biodiesel Production via Hydroesterification. Enzyme Research, v. 2011, 1-8, 2011.

PRADO, G. H. C.; SALDAÑA, M. D. A. Optimization of Enzymatic Hydrolysis of Sacha Inchi Oil using Conventional and Supercritical Carbon Dioxide Processes. Journal of the American Oil Chemists' Society, v. 90, 731-742, 2013.

PRATES, F. B. S. et al. Acúmulo de nutrientes e produtividade de crambe em função da fertilização com torta de mamona e serpentinito. Ciência Rural, v. 44, 810-816, 2014.

RANGANATHAN, S. V.; NARASIMHAN, S. L.; MUTHUKUMAR, K. An overview of enzymatic production of biodiesel. Bioresource Technology, v. 99, 3975-3981, 2008. 
RASPE, D. T.; CARDOZO-FILHO, L.; SILVA, C. Effect of additives and process variables on enzymatic hydrolysis of macauba kernel oil (Acrocomia aculeata). International Journal Chemical Engineering, v. 2013, 01-08, 2013.

RIBEIRO, B. D.; COELHO, M. A.; BARRETO, D. W. Production of concentrated natural beta-carotene from buriti (Mauritia vinifera) oil by enzymatic hydrolysis. Food and Bioproducts Processing, v. 90, n. 2, 141147, 2012.

SANTOS, J. I. et al. Yield response in crambe to potassium fertilizer. Industrial Crops Products, v. 43, 297-300, 2013.

SATYARTHI, J. K.; SRINIVAS, D.; RATNASAMY, P. Hydrolysis of vegetable oils and fats to fatty acids over solid acid catalysts. Applied Catalysis A: General, v. 391, 427-435, 2011.

SILVA, M. A. et al. Qualidade do óleo bruto de grãos de crambe (Crambe abyssinica Hochst) sob diferentes métodos de secagem. Energia na Agricultura, v. 28, n. 3, 193-199, 2013.

SILVA, T. R. B.; REIS, A. C. S.; MACIEL, C. D. G. Relationship between chlorophyll meter readings and total $\mathrm{N}$ in crambe leaves as affected by nitrogen topdressing. Industrial Crops and Products, v. 39, 135-138, 2012.

SOO, E. L. et al. Response surface methodological study on lipase-catalyzed synthesis of amino acid surfactants. Process Biochemistry, v. 39, 1511-1518, 2004.

TAKISAWA, K. et al. Hydrolysis for direct esterification of lipids from wet microalgae. Bioresource Technology, v. 144, 38-43, 2013.
TALUKDER, M. R.; WU, J. C.; CHUA, L. P. L. Conversion of waste cooking oil to biodiesel via enzymatic hydrolysis followed by chemical esterification. Energy Fuels, v. 24, 2016-2019. 2010.

THANK, L. T. et al. Ultrasound-assisted production of biodiesel fuel from vegetable oils in a small scale circulation process. Bioresource Technology, v. 101, 639-645, 2010.

VELJKOVIĆ, V. B, et al. Biodiesel production by ultrasound-assisted transesterification: State of the art and the perspectives. Renewable and Sustainable Energy Reviews, v. 16, n. 2, 1193-1209, 2012.

VIANA, O. $\mathrm{H}$. et al. Productivity in relation to spatial arrangement and fertilization in the culture of Crambe abyssinica Hochst. Journal of Food Agriculture \& Environment, v. 11, 721-723, 2013.

VIKBJERG, A. F. et al. Continuous Production of Structured Phospholipids in a Packed Bed Reactor with Lipase from Thermomyces lanuginosa. Journal of the American Oil Chemists' Society, v. 82, 237242, 2005.

WALKER, R. E. Official Methods and Recommended Practices of the American Oil Chemists' Society (Method AOCS Ca 5a-40). 5th ed. United States: Champaign, 1998.

WAZILEWSKI, W. T. et al. Study of the methyl crambe (Crambe abyssinica Hochst) and soybean biodiesel oxidative stability. Industrial Crops and Products, v. 43, 207-212, 2013.

YU, D. et al. Ultrasonic irradiation with vibration for biodiesel production from soybean oil by Novozym 435. Process Biochemistry, v. 45, 519-525, 2010. 